\title{
Dune geometry estimation using apparent bedload velocity as predictor variable
}

\author{
Gordon Gilja ${ }^{1, *}$, and Neven Kuspilić ${ }^{1}$ \\ ${ }^{1}$ University of Zagreb, Faculty of Civil Engineering, Water research department, 10000 Zagreb, \\ Croatia
}

\begin{abstract}
Dune formation in river systems influences sediment transport, flow characteristics, bank erosion, flood control, navigation and the protection of land and infrastructure. Research on dunes is mainly flumebased, and conclusions from such research are rarely, if at all, verified with field measurements. Dune formation and geometry in terms of height, length and steepness is most commonly correlated with averaged flow parameters as flow depth. Application of relations defined in flume conditions is limited due to stationary flow conditions and extrapolation issues for natural watercourses. It is reasonable to assume that apparent bedload velocity has significant influence on dune field formation due to nature of movement of sand particles across sandy riverbed. This research investigates applicability of apparent bedload velocity as argument in empirical relations for dune geometric characteristics.
\end{abstract}

\section{Introduction}

Formation of dunes in rivers generates complex riverbed geometry that significantly influences flow pattern in open watercourses $[1,2]$. Dunes influence sediment transport, flow characteristics, bank erosion, flood control, navigation and the protection of land and infrastructure. Most common types of bedforms are dunes which directly influence flow pattern throughout the water column by inducing additional form friction through change in dynamical pressure distribution over the riverbed. Form friction generated by dunes protruding into the flow field is important for calculation of water levels along the river reach for specific design flood event. Therefore, characteristics of dune field and flow pattern over them have been presenting a challenge for alluvial morphodynamic research for decades [3].

Dune geometry is most commonly described by empirical models developed in laboratory flumes for steady and uniform flow conditions. Conclusions from flume-based dune research are rarely, if at all, verified with field measurements. Due to the restrictions imposed by flume setup, dune formation and geometry in terms of height, length and steepness is most commonly correlated with averaged flow parameters that are easily measured and related to 2D flow field, e.g. flow depth which is the limiting factor of dune growth and is therefore best used to examine the response of dunes to their flow environment [4].

* Corresponding author: gordon.gilja@grad.hr 


\section{Current research}

Application of empirical relations defined in flume conditions is limited due to (1) steady flow conditions that do not fully reflect natural flow characteristics and (2) extrapolation issues for natural watercourses emerging from scaling down both flow and sediment properties. This field of research was studied extensively, e.g. by Allen, van Rijn, Yalin, etc. resulting with numerous empirical relations that enable estimation of dune height and length from flow depth measurements [4-10]. From aforementioned studies measured data was extracted in order to use in analysis presented in this research. Selected empirical equations were used to determine difference between calculated and measured values of dune geometry from the available data. Benchmark geometry data was extracted from Gabel's study [11], study by Ali et al. [5], and the Prent-Hickin study [4] and is characterized with variety of combinations of flow depth and velocity. Relative difference $\Delta$ between measured and calculated geometry is calculated using following equation (example for dune length $\lambda$ ):

$$
\Delta(\lambda)=\mid \lambda_{\text {calculated }}-\lambda \text { measured } \mid / \lambda \text { measured }
$$

where: $\Delta(\lambda)$ - relative difference between measured and calculated geometry [\%], $\lambda_{\text {calculated }}$ - calculated data $[\mathrm{m}], \lambda_{\text {measured }}$ - measured data $[\mathrm{m}]$.

The comparison of measured and calculated dune geometry data for different models is given as separate boxplot for each analysed equation in the following figure.
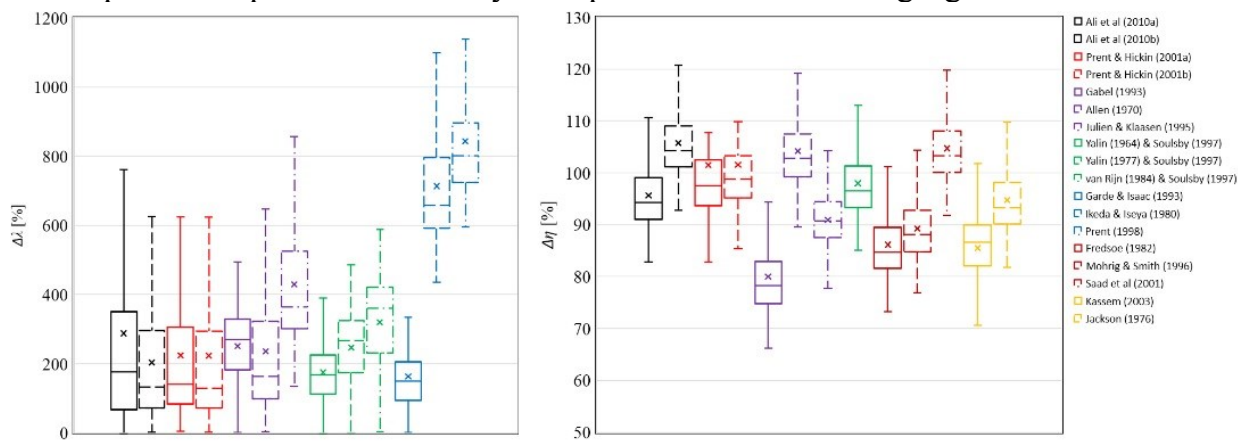

Fig. 1. Boxplot of difference between measured and calculated values for dune geometry: length (left) and height (right) [12]

Comparison of the combined results for aforementioned studies given in Fig. 1. shows significant discrepancy of the results. Dune length can be overestimated or underestimated, depending on the equation used, up to $1289 \%$, with mean value of $537 \%$. Dune height shows smaller dissipation of the results because it is usually an order of magnitude smaller than length, which in turn results with smaller scatter of measured values: dune height can be overestimated or underestimated up to $105 \%$, with mean value of $95 \%$. Differences shown for analysed datasets show that flow depth has significant constraints and cannot be reliably used as predictor for dune formation across riverbeds with flow regime different from the one initially used for development of the equation.

Research conducted on field survey data by Bartholdy et al. and Ikeda and Iseya has shown to be characterized by large scatter when compared against empirical model data. This is mostly due to the increase in energy grade slope, and consequently shear stress, during flood events which initiates sediment transport even when water depth remains constant. In accordance with this assumption, several studies have shown linear relationship 
of both the dune length and height on the flow velocity for their dataset (Prent and Hickin [4], Jackson and Gabel [13], Babakaiff and Hickin [14]).

Results of experimental studies show that impulse is more important than force for incipient motion of sediment particles. The influence of impulse is highlighted in cases when instantaneous peaks of fluctuating velocity components exceed the time averaged bed-shear velocity and initiate particle movement, as is common in dune covered riverbed [15]. Rennie [16] showed that correlation between the apparent bedload velocity and bedload sediment transport is stronger than the one between apparent bedload velocity and shear stress. Therefore, is reasonable to assume that apparent bedload velocity has significant influence on dune field formation due to nature of movement of sand particles across sandy riverbed. This research investigates applicability of apparent bedload velocity as argument in empirical relations for dune geometric characteristics.

\section{Data collection}

Study reach selected for research was $1 \mathrm{~km}$ long section of the Drava River in its lower course in Croatia, spanning from rkm $14+000$ to $\mathrm{rkm} 15+000$. Study reach is straight, adjacent to the upstream right-hand bend. River is in natural, unaltered conditions upstream of the study reach, while there are river training structures placed on the right-hand bank in the downstream part of the study reach. Survey data was collected using hydroacoustic equipment for simultaneous measurement of velocity profile and bathymetry data. Flow field characteristics are defined through cross-sectional flow velocity profiles collected on independent surveys on control river cross-sections using Acoustic Doppler Current Profiler (ADCP). For each cross-section ADCP transect was made to collect flow velocity profile, cross-section geometry and discharge. Dune field bathymetry was collected using Multibeam Echo Sounder (MBES) deployed on longitudinal section of Drava River spanning across several ADCP cross-sections. Hydroacoustic equipment was paired with RTK-GPS which enabled georeferencing and synchronization of collected data in the same Cartesian coordinate system.

Advantages of ADCP type instruments is reliability of use in unsteady flow conditions and fast data acquisition, enabling data acquisition on large river reaches during single flow event, as well as three-dimensional velocity vector measurements. The ADCP instrument simultaneously measures its own movement over the riverbed VBT and relative flow velocity vb. From these measured values absolute flow velocity vector vw is directly calculated [17]. Boat velocity VBT calculated this way can be biased in case the riverbed is movable due to the bedload sediment transport, which often is the case [17-21]. In cases when moveable bed is expected, absolute boat velocity vector VGGA can be measured with additional instrument (GPS), thus eliminating the possibility of bias introduction into the absolute_flow velocity calculation. When GPS is used to measure absolute boat velocity, the apparent bedload velocity can be calculated as the difference between the two measured boat velocity vectors:

$$
\mathbf{v}_{\mathbf{b}}=\mathbf{V}_{\mathbf{G G A}}-\mathbf{V}_{\mathbf{B T}}
$$

where: $\mathbf{v}_{\mathbf{b}}$ - apparent bedload velocity vector, $\mathbf{v}_{\mathbf{G G A}}=$ absolute boat velocity vector from GPS, VBT - relative boat velocity vector measured by the ADCP's bottom-tracking feature.

Apparent bedload velocity cannot be measured directly - it must be calculated during post-processing of the acquired data from data collecting software output files. For this purpose, method for apparent bedload velocity calculation from collected survey database was developed. This method is implemented through algorithms and incorporated in 
software for data analysis during post processing of raw ADCP files and defines comprehensive approach for description of dune field characteristics based on measured velocity profile.

Collected data is used as input to obtain averaged flow parameters across river reach for comparison with traditional empirical relations. 1D numerical model calibrated for each survey is used to calculate flow averaged variable across the river reach. Results obtained from field survey and 1D numerical model are coupled together on cross-sections in order to represent one hydrological event. In this research apparent bedload velocity is introduced as argument in regression analysis for dune geometry and results are compared with results from empirical relations.

\section{Results}

Dune geometry data extracted from multibeam surveys on Drava River is plotted against available empirical models from literature [10]. In Fig. 2. is given scatter plot of measured data pairs of dune lengths and respective flow depths. It is visible that measured data lies in the bottom section covered by available empirical models, i.e. that for similar flow conditions dunes with smaller length are observed on Drava River. Linear regression line is fitted to the data, excluding survey $u 5$ that is conducted during backwater effect resulting from high flow on the Danube River into which Drava River inflows. Regression shows that with increase in flow depth increase in dune length can be expected, consistent with empirical model data. Fitted linear regression shows very weak relationship between the flow depth and dune length with coefficient of determination value $R^{2}=0.1$.

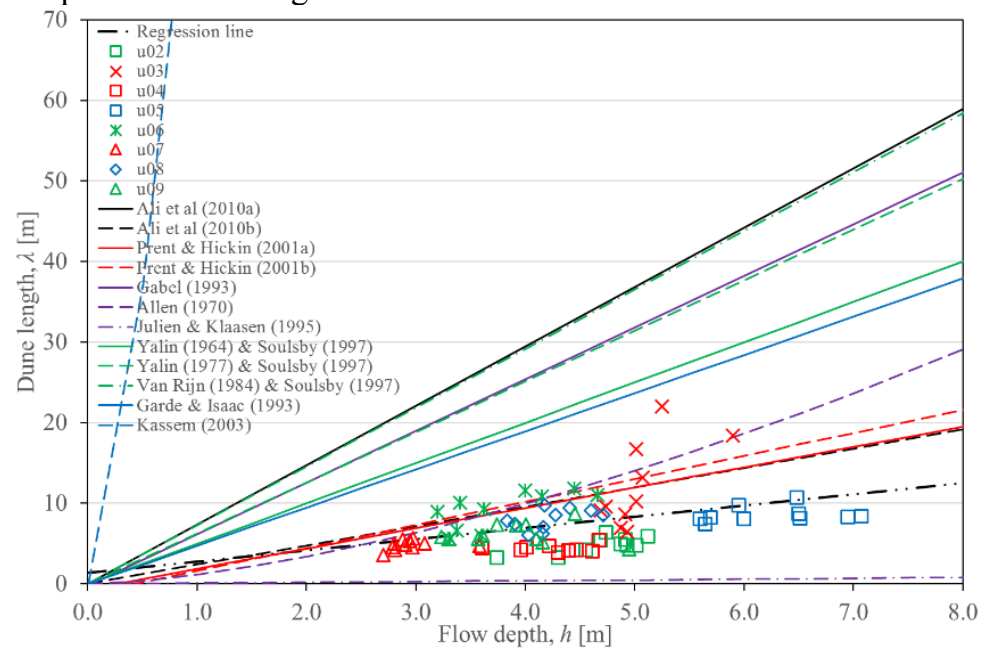

Fig. 2. Scatter plot of measured data for dune length and flow depth

In Fig. 3. is given scatter plot of measured data pairs of dune heights and respective flow depths. Measured data lies mostly in the bottom section covered by available empirical models, consistent to dune length data. Linear regression shows that with increase in flow depth increase in dune length can be expected, as it was the case for dune length. Fitted linear regression shows very weak relationship between the flow depth and dune height with coefficient of determination value $R^{2}=0.11$. 


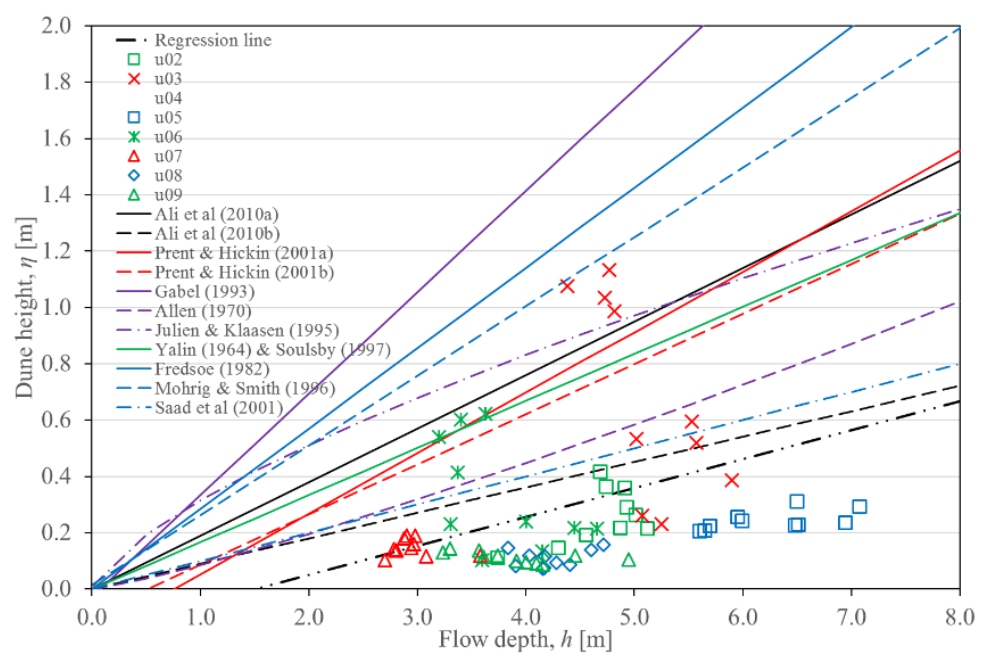

Fig. 3. Scatter plot of measured data for dune height and flow depth

When empirical relationships are deployed for dune geometry estimation, in most cased only single predictor variable is used which doesn't necessarily reflect the complexity of the processes involved in dune formation, growth or migration. Complex interaction between the turbulent flow field, sediment transport and bedform geometry is difficult to encompass in single and applicable manner, while errors in their estimation are mostly accepted due to the uncertainties related to the data acquisition which makes empirical models acceptable for most practical engineering purposes. Direct measurements of bedload sediment transport are rarely available, so different variable that reflects bedload sediment must be used to estimate dune properties. Calculation of apparent bedload velocity enables insight of the bedload sediment movement as direct measure of the moving sediment particles across dune field.

In the following figure is given scatter plot of measured data pairs of dune lengths and heights vs respective apparent bedload velocity. Regression line fitted the same way as for traditional relationships shows increase in relationship strength, with increase of $R^{2}$ value to 0.27 and 0.78 for dune length and height, respectively (Fig. 4.).
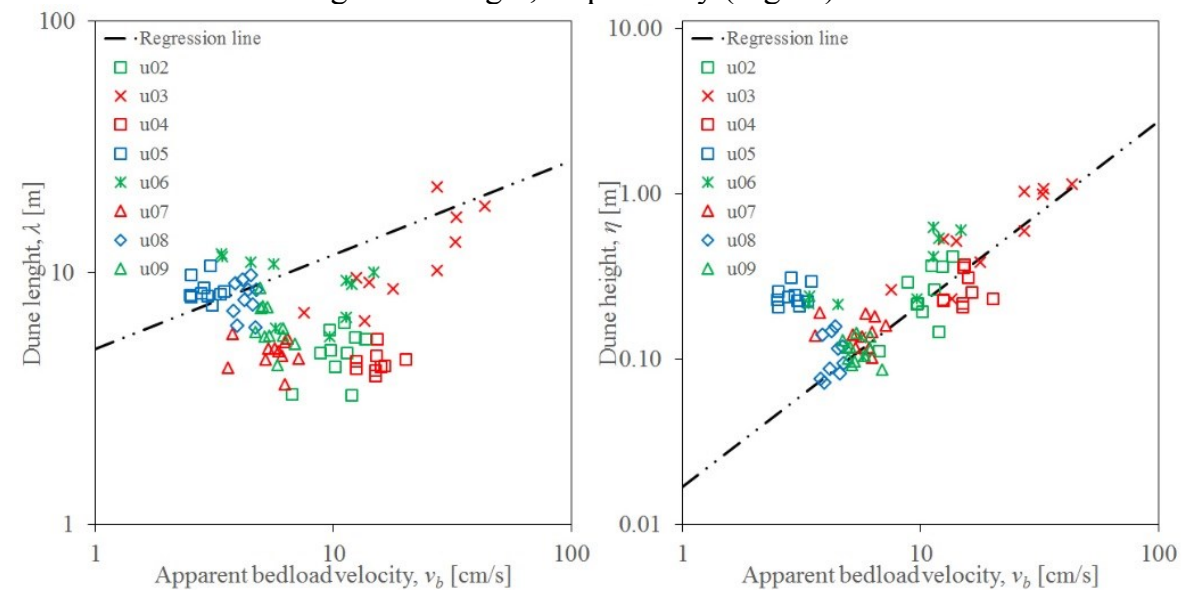

Fig. 4. Scatter plot of measured data for dune length (left) and height (right) vs apparent bedload velocity (adapted from [10]) 
Empirical relationship defined this way shows that if apparent bedload velocity is introduced as predictor variable regression strength increases in comparison to flow depth, both for dune length and height. Dune height follows linear regression that strongly correlates to the apparent bedload velocity, while for dune length it is visible that relationship is curved with minimal dune lengths around the value of apparent bedload velocity of $10 \mathrm{~cm} / \mathrm{s}$.

In this study all available data was used for large span of discharges, ranging from 300 $\mathrm{m}^{3} / \mathrm{s}$ to $1200 \mathrm{~m}^{3} / \mathrm{s}$, while mean flow discharge is $552 \mathrm{~m}^{3} / \mathrm{s}$. However, measured dataset is limited, and therefore more measurements are needed to confirm trend shown in this research. Current dataset can easily be extended in a way that single dunes can be addressed and local flow velocity field above them identified from ADCP data. Empirical relationships established within this study can be used for dune geometry estimation as follows:

$$
\lambda=5.1124 v_{b}^{0.1131}
$$

where: $\lambda$ - dune length $[\mathrm{m}], v_{b}$ - apparent bedload velocity $[\mathrm{cm} / \mathrm{s}]$; and

$$
\eta=0.0295 v_{b}^{0.9196}
$$

where: $\eta$-dune height $[\mathrm{m}]$.

\section{Conclusion}

Results of conducted research confirm shortcomings of traditionally used variables for dune estimation. It is shown that dune research should be founded on field experiments that encompass all of the variables controlling dune formation and geometry, foremost apparent bedload velocity. For analysed dataset collected on Drava River it is shown that apparent bedload velocity is more accurate predictor of dune geometry than flow depth. Measured data show strong correlation when apparent bedload velocity is introduced as predictor variable into empirical relationships, but trend must be further analysed and supplemented with additional data to augment current dataset. Additional research must be conducted oriented towards more specific hydraulic conditions to further investigate the role that apparent bedload velocity plays in dune formation. Recent widespread use of the apparent bedload velocity in riverine research could result in its addition as direct output variable from data collecting software, which could enable further more detail research of its role in the sedimentological processes.

\section{References}

1. R. Mazumder, J. Afr. Earth Sci., 36, 1-14 (2003)

2. M. Omidyeganeh, U. Piomelli, Seventh International Symposium on Turbulence and Shear Flow Phenomena, (2011)

3. S. Coleman, Experimental Methods in Hydraulic Research, 1-27 (2011)

4. M.T.H. Prent, E.J. Hickin, Geomorphology, 41, 369-390 (2001)

5. M. Ali, K. Attia, A. El Bahrawy, Nile Basin Water Science \& Engineering Journal, 3, 14-25 (2010)

6. P.A. Carling, E. Gölz, H.G. Orr, A. Radecki-Pawlik, Sedimentology, 47, 227-252 (2000) 
7. M.H. Garcia, Sedimentation Engineering: Processes, Measurements, Modeling, and Practice (ASCE, 2008)

8. M.T. Clunie, Flow Over Fluvial Bedforms, (The University of Auckland, 2012)

9. L.C. van Rijn, J. Hydraul. Eng., 110, 1733-1754 (1984)

10. G. Gilja, N. Kuspilić, K. Potočki, Građevinar, 69, 427-436 (2017)

11. S.L. Gabel, Sedimentology, 40, 237-269 (1993)

12. G. Gilja, N. Kuspilić, 9th Eastern European Young Water Professionals Conference, 67-68 (2017)

13. R.G. Jackson, J. Fluid Mech., 77, 531-560 (1976)

14. S.C. Babakaiff, Bedforms And Macroturbulence Of Squamish River Estuary, British Columbia, (Simon Fraser University, 1993)

15. P. Diplas, C.L. Dancey, A.O. Celik, M. Valyrakis, K. Greer, T. Akar, Science, 322, 717-720 (2008)

16. C.D. Rennie, R.G. Millar, M.A. Church, J. Hydraul. Eng., 128, 473-783 (2002)

17. M.R. Simpson, Discharge Measurements Using a Broad-Band Acoustic Doppler Current Profiler, (U.S. Geological Survey, 2001)

18. P.V. Villard, M.A. Church, R. Kostaschuk, Fluvial sedimentology VII, 197-209 (2005)

19. C.D. Rennie, F. Rainville, S. Kashyap, J. Hydraul. Eng., 133, 1337-1344 (2007)

20. C.R. Wagner, D.S. Mueller, J. Hydrol., 401, 250-258 (2011)

21. G. Gilja, D. Bekić, N. Kuspilić, Current events in hydraulic engineering, 123-135 (2011) 